Article

\title{
Effect of Cooling Rate on Microstructure and Grain Refining Behavior of In Situ $\mathrm{CeB}_{6} / \mathrm{Al}$ Composite Inoculant in Aluminum
}

\author{
Shuiqing Liu, Chunxiang Cui *, Xin Wang, Nuo Li, Jiejie Shi, Sen Cui and Peng Chen \\ Key Laboratory for New Type of Functional Materials in Hebei Province, School of Materials Science and \\ Engineering, Hebei University of Technology, Tianjin 300130, China; liushuiqing0824@126.com (S.L.); \\ ahaxin@126.com (X.W.); ln0713@126.com (N.L.); s13820443711@126.com (J.S.); m15122133732@126.com (S.C.); \\ m15900225021@163.com (P.C.) \\ * Correspondence: hutcui@hebut.edu.cn; Tel.: +86-022-2656-4125; Fax: +86-022-6020-4125
}

Academic Editor: Murat Tiryakioglu

Received: 28 April 2017; Accepted: 31 May 2017; Published: 2 June 2017

\begin{abstract}
Melt spinning was performed to process an in situ $\mathrm{CeB}_{6} / \mathrm{Al}$ inoculant at different rotating speeds to investigate the influence of cooling rate on the grain refining behavior of inoculants. It has been found that a high cooling rate caused two obvious changes in the inoculant: the supersaturated solid solution of $\mathrm{Ce}$ in the $\alpha$ - $\mathrm{Al}$ matrix and the miniaturization of $\mathrm{CeB}_{6}$ particles. At high cooling rates of $\sim 10^{8} \mathrm{~K} / \mathrm{s}$, the Ce content is largely beyond the theoretical solid solubility of $\mathrm{Ce}$ in $\mathrm{Al}$, and the size of the $\mathrm{CeB}_{6}$ particles in ribbons is reduced to $\sim 100 \mathrm{~nm}$. The grain refining effect of melt-spun $\mathrm{CeB}_{6} / \mathrm{Al}$ composite inoculant shows significant dependence on holding time of which the best value should be no more than $2 \mathrm{~min}$. The excellent grain refinement of the inoculant can be attributed to the combined effect of the nano-sized refiner particles and the large undercooling caused by the sudden melting of supersaturated Al-Ce solution.
\end{abstract}

Keywords: melt spinning; in situ Al matrix composite; Inoculation; Cerium hexaboride; microstructure; mechanism

\section{Introduction}

Grain refinement in aluminum alloys has obtained much attention in the casting industry, due to the significant enhancement of mechanical performance with the addition of minute quantities of inoculant $[1,2]$. To improve the grain refining efficiency of inoculation, many methods and strategies have been proposed, including chemical modification [3], rapid solidification [4-8], and ultrasonic processing [9], etc. Meanwhile, many theoretical and experimental investigations have aimed at revealing the procedure when inoculants are added to melts [10-13]. However, the detailed behavior of the interaction of different grain refiners with aluminum melt during grain refining treatment has not yet been fully understood.

As typical rapid solidification technology, melt spinning has been paid much attention for microstructure refinement, chemical homogeneity and improvement of solid solubility $[8,14,15]$. In particular, it is possible to promote the formation of ultra-fine secondary phase particles when the cooling rate exceeds $10^{4} \mathrm{~K} / \mathrm{s}$ [16-18]. For example, $\mathrm{Xu}$ et al. [19] proposed that when the cooling rate of $\mathrm{Al}-20 \mathrm{wt}$. $\% \mathrm{Si}$ is $1.11 \times 10^{6} \mathrm{~K} / \mathrm{s}$, the size of primary silicon is drastically changed from 5 to $500 \mathrm{~nm}$. Karaköse and Keskin [20] studied the effects of different cooling rates on the microstructure of Al-8Si-Sb ribbon and found 2.7 times improvements in hardness. Recently, Dong et al. [21] investigated the formation of $\mathrm{Al}-9 \mathrm{Si}-\mathrm{Cu}$ ribbons with a thickness of $54 \mu \mathrm{m}$ and found that very fine and homogeneous Si particles are disperse in Al matrix. Since melt-spinning has such significant effect 
on refining the high-melting point phase in aluminum alloys, it also raises attention on processing of inoculant [22-24].

Recently, we used an arc-melt-spinning technique to prepare an in situ $\mathrm{CeB}_{6} / \mathrm{Al}$ inoculant and showed that it is very effective for refining aluminum [25]. We also developed a low-temperature synthesis method to optimize this inoculant and found that the melt-spun inoculant contains sub-micron $\mathrm{CeB}_{6}$ clusters and low-melting-point $\mathrm{Al}-\mathrm{Ce}$ phase [26]. To examine the refining effect of this inoculant under more casting conditions, we did the inoculation experiment under different holding time that is considered an important parameter to measure the performance of the inoculant $[27,28]$. We found that the cooling rate is also effective on holding time and we proposed a stationary model to explain the corresponding mechanism.

\section{Materials and Methods}

Commercial Al-20Ce (in wt. \%) and Al-3B (in wt. \%) alloys were used as starting materials to prepare the Al-B-Ce master alloy in a graphic crucible (Yihui casting factory, Guangzhou, China) by arc melting under an argon atmosphere. During melting, the temperature of the reaction melt was monitored by a double color infrared laser thermometer (Fluke factory, Shanghai, China). Then the master alloy was re-melted by induction melting and blew on a single copper roller (Chinese academy of science, three-ring long magnetic equipment factory, Jiangsu, China) with a diameter of $22 \mathrm{~cm}$ to prepare the $\mathrm{CeB}_{6} / \mathrm{Al}$ ribbons. The rotating speed of the copper roller was set as 2000 and $8000 \mathrm{rpm}$, respectively (denoted as $\mathrm{C} 1$ and $\mathrm{C} 2$ ). In contrast, the casting obtained using a copper mold [29] with a diameter of $10 \mathrm{~cm}$ was denoted as alloy $\mathrm{C} 0$.

The $\mathrm{CeB}_{6} / \mathrm{Al}$ ribbons with different rotating speeds were used as inoculants and added into aluminum melt at $720{ }^{\circ} \mathrm{C}$ with an adding ratio of $0.4 \%$ that has been confirmed as the best addition amount previously [25]. After different holding times (1,2,5, and $30 \mathrm{~min})$, the treated melts were stirred for $10 \mathrm{~s}$ and then poured into a steel mold with a cavity of $20 \mathrm{~mm}$ in diameter and $120 \mathrm{~mm}$ in height. The specimens for metallographic examination were cut from the middle part of each as-cast rod and carefully grinded by sandpaper. After mechanical polishing, the specimens were etched with Poulton's reagent $\left(60 \% \mathrm{HCl}+30 \% \mathrm{HNO}_{3}+5 \% \mathrm{HF}+5 \% \mathrm{H}_{2} \mathrm{O}\right)$ for macroscopic observation. Next, the specimens were re-polished and etched in a $0.5 \%$ vol. $\% \mathrm{HF}$ solution for microscopic observation using optical microscope (OM, Olympus, Jiang dong ou yi testing instrument, Ningbo, China). The grain size of each sample was measured using the intercept method according to ASTM standard E112.

The specimens were characterized by Bruker D8 Discover X-ray diffraction (XRD, Bruker AXS, Karlsruhe, Germany) with $\mathrm{Cu}$ Ka radiation, S4800 scanning electron microscope (SEM, Hitachi, Tokyo, Japan) and Olympus optical microscope (OM). High-Resolution Transmission Electron Microscope (HRTEM) was performed on a JEOL 2000FX instrument (Shimadzu Corporation, Kyoto, Japan).

\section{Results}

\subsection{Confirmation of Cooling Rate}

Figure 1 shows the curves plotted using the temperature versus cooling rate. The thickness of the $\mathrm{CeB}_{6} / \mathrm{Al}$ ribbons produced by different rotating speed of copper wheel $\mathrm{C} 1$ and $\mathrm{C} 2$ is about 136 and $14 \mu \mathrm{m}$, respectively. As is well known, the thickness of spinning ribbon relates to the cooling rate of the melt during the solidification. Therefore, the actual cooling rates of the $\mathrm{CeB}_{6} / \mathrm{Al}$ ribbons and solidification times can be calculated from their thicknesses. The cooling rate of a ribbon is governed by the Fourier's equation of heat transfer [19], as follows:

$$
\begin{aligned}
\frac{\partial T}{\partial t} & =\alpha \frac{\partial T^{2}}{\partial x^{2}} \\
\alpha & =k / c \rho
\end{aligned}
$$


where $T, t, \alpha, c$, and $\rho$ are temperature (K), cooling time (s), thermal conductivity $(\mathrm{W} /(\mathrm{m} \cdot \mathrm{K}))$, specific heat capacity $(\mathrm{J} /(\mathrm{kg} \cdot \mathrm{K}))$, and density $\left(\mathrm{kg} / \mathrm{m}^{3}\right)$, respectively. According to the literature [18], the thermal storage coefficient $b=\sqrt{k c \rho}\left(\mathrm{W} \sqrt{\mathrm{S}} /\left(\mathrm{m}^{2} \cdot \mathrm{K}\right)\right)$, the ribbon-wheel interface temperature $T_{\mathrm{i}}$ can be expressed as

$$
T_{\mathrm{i}}=\frac{b_{1} T_{10}+b_{2} T_{20}}{b_{1}+b_{2}}
$$

So, the temperature distribution of the melt spinning ribbon can be obtained as

$$
T_{1}=T_{\mathrm{i}}+\left(T_{\mathrm{i}}-T_{10}\right) \operatorname{erf}\left(\frac{\chi}{2 \sqrt{\alpha_{1} t}}\right)
$$

Taking the temperature $T$ as a function of the cooling time $t$, the cooling rate at the thickness $\chi$ is given by

$$
\left[\frac{\partial T_{1}}{\partial t}\right]_{\chi}=-\frac{b_{2}\left(T_{20}-T_{10}\right) \chi}{2\left(b_{1}+b_{2}\right) t \sqrt{\pi \alpha_{1} t}} \exp \left[-\left(\frac{\chi}{2 \sqrt{\alpha_{1} t}}\right)^{2}\right]
$$

The solidification time of melt spinning ribbon can be obtained from

$$
t_{s}=\left\{\frac{\sqrt{\pi} \chi \rho_{1}\left[L+c_{1}\left(T_{10}-T_{\mathrm{s}}\right)\right]}{2 b_{2}\left(T_{\mathrm{i}}-T_{20}\right)}\right\}^{2}
$$

where $L$ is the latent heat of aluminum. The values of the parameters we used are according to the reference [19], which are all listed in Table 1. Figure 1 shows the curves plotted using the temperature versus cooling rate based on Equation (3). By taking the melt point temperature of pure $\mathrm{Al}$ as the solidification temperature, the average cooling rates of different thicknesses ribbons are then the derivative values of the nodes, which are $8.4 \times 10^{2} \mathrm{~K} / \mathrm{s}, 5.1 \times 10^{5} \mathrm{~K} / \mathrm{s}$, and $1.6 \times 10^{8} \mathrm{~K} / \mathrm{s}$, respectively. Obviously, the ribbons with thickness difference of about 1000 times show great difference of about three orders of magnitude in the corresponding cooling rates.

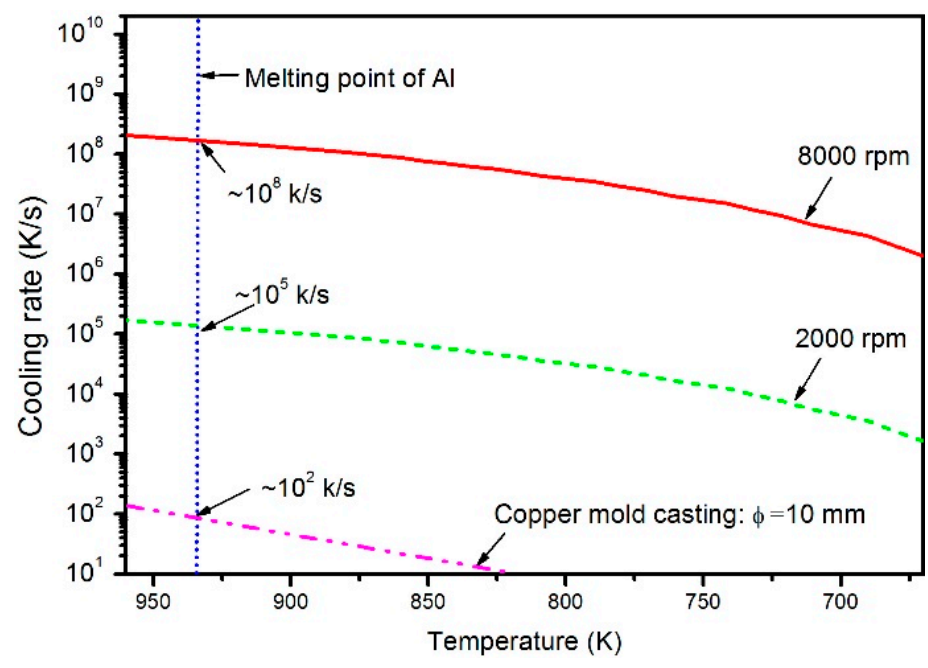

Figure 1. Temperature versus cooling rate plots of different $\mathrm{CeB}_{6} / \mathrm{Al}$ inoculant during solidification. 
Table 1. Modeling parameters used to estimate the cooling rate [19].

\begin{tabular}{ccc}
\hline Parameters & Material & Material \\
\cline { 2 - 3 } & $\mathbf{A l}$ & Wheel \\
\hline Initial temperature, $\boldsymbol{T}_{\mathbf{0}}(\mathrm{K})$ & $1123\left(\boldsymbol{T}_{\mathbf{1 0}}\right)$ & $293\left(\boldsymbol{T}_{\mathbf{2 0}}\right)$ \\
Thermal conductivity, $\boldsymbol{k}(\mathrm{W} /(\mathrm{m} \cdot \mathrm{K}))$ & $237\left(\boldsymbol{k}_{\mathbf{1}}\right)$ & $398\left(\boldsymbol{k}_{\mathbf{2}}\right)$ \\
Specific heat capacity, $\boldsymbol{c}(\mathrm{J} /(\mathrm{kg} \cdot \mathrm{K}))$ & $880\left(\boldsymbol{c}_{\mathbf{1}}\right)$ & $386\left(\boldsymbol{c}_{\mathbf{2}}\right)$ \\
Density, $\boldsymbol{\rho}\left(\mathrm{kg} / \mathrm{m}^{3}\right)$ & $2700\left(\boldsymbol{\rho}_{\mathbf{1}}\right)$ & $8930\left(\boldsymbol{\rho}_{\mathbf{2}}\right)$ \\
Coefficient in Fourier's equation, $\boldsymbol{\alpha}=\boldsymbol{k} / \boldsymbol{c} \boldsymbol{\rho}$ & $23729.98\left(\boldsymbol{b}_{\mathbf{1}}\right)$ & $37,039\left(\boldsymbol{b}_{\mathbf{2}}\right)$ \\
Latent heat of $\mathrm{Al}, \boldsymbol{L}(\mathrm{kJ} / \mathrm{kg})$ & $9.59 \times 10^{-5}\left(\boldsymbol{\alpha}_{\mathbf{1}}\right)$ & - \\
Thermal storage cofficient $\boldsymbol{K}$ & 396.67 & - \\
Ribbon-wheel interface temperature $\boldsymbol{T}_{\mathbf{i}}=\left(\boldsymbol{b}_{\mathbf{1}} \boldsymbol{T}_{\mathbf{1 0}}+\boldsymbol{b}_{\mathbf{2}} \boldsymbol{T}_{\mathbf{2 0}}\right) /\left(\boldsymbol{b}_{\mathbf{1}}+\boldsymbol{b}_{\mathbf{2}}\right)(\mathrm{K})$ & 617.11 & - \\
Solidus temperature, $\boldsymbol{T}_{\boldsymbol{s}}(\mathrm{K})$ & 933.37 & - \\
Thickness of the ribbons, $\chi(\mu \mathrm{m})$ & - & - \\
\hline
\end{tabular}

\subsection{Effect of Cooling Rate on the Microstructure}

The XRD patterns of the $\mathrm{C} 0, \mathrm{C} 1$, and $\mathrm{C} 2$ alloy are shown in Figure 2. All the XRD spectra are presented with obvious peaks of $\alpha-\mathrm{Al}$ and $\mathrm{CeB}_{6}$ phase, indicating the successful synthesis of $\mathrm{CeB}_{6}$ phase. In theory, the successful synthesis of $\mathrm{CeB}_{6}$ might be attributed to the energy status of the active $\mathrm{Ce}$ atoms and $\mathrm{B}$ atoms due to the presence of liquid $\mathrm{Al}$ melt. Besides, the enlarged view of XRD spectrum of the ribbon samples produced by different rotating speed is shown as Figure $2 \mathrm{~b}$. It is noticed that some weak peaks of $\mathrm{Al}_{11} \mathrm{Ce}_{3}$ are also detected in $\mathrm{C} 0$ alloy. However, with the cooling rate increased, the peak of $\mathrm{Al}_{11} \mathrm{Ce}_{3}$ phase disappears.
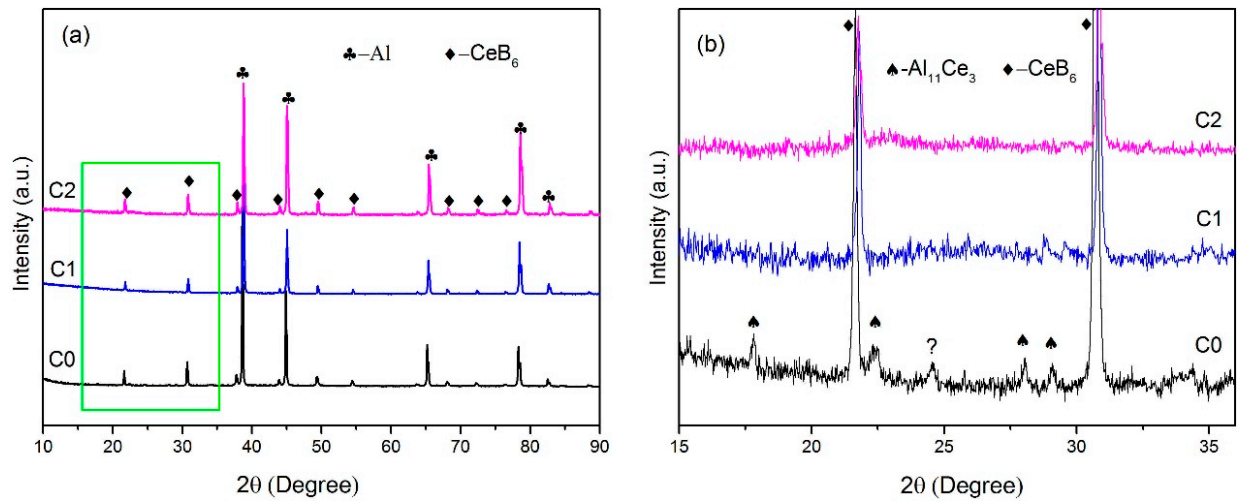

Figure 2. (a) X-ray diffraction (XRD) spectrum of the inoculant alloys with different cooling rates. (b) The enlarged view of XRD spectrum in the (a).

Figure 3 shows the TEM images of the $\mathrm{C} 3$ ribbon. It is found that some particles with an average size of about $100 \mathrm{~nm}$ are dispersing in the matrix. To further confirm the particles and matrix shown in Figure 3, the electron diffraction data are shown as the inset in Figure 3. It is indicated that the particles are $\mathrm{CeB}_{6}$ phase and the matrix is $\mathrm{Al}$, which is in accordance with the XRD results shown in Figure 2.

Figure 4 shows the SEM images of the $\mathrm{C} 0$ and $\mathrm{CeB}_{6} / \mathrm{Al}$ ribbons produced by different cooling rates. As shown in Figure 4a, many white particles with different sizes, which are aggregated in the matrix. It should be noted that in the $\mathrm{C} 0$ alloy with cooling rate of $\sim 10^{2} \mathrm{~K} / \mathrm{s}$, the particles are agglomerated and size is in a range of $1-18.9 \mu \mathrm{m}$ as shown in Figure 4a. With the increase of cooling rate to $\sim 10^{5} \mathrm{~K} / \mathrm{s}$ (C1 alloy), the size of the particles is further reduced to $1-9.5 \mu \mathrm{m}$ as shown in Figure $4 \mathrm{~b}$. Furthermore, when the cooling rate is up to $\sim 10^{8} \mathrm{~K} / \mathrm{s}$, the size of $\mathrm{CeB}_{6}$ particles is reduced to $\sim 100 \mathrm{~nm}$ as shown in the Figure 4c (C2 alloy). Moreover, the particles in $\mathrm{C} 2$ ribbon are more homogeneously distributed in the $\mathrm{Al}$ matrix with an almost ideal dispersion degree. Therefore, our results show that melt spinning can significantly alter the microstructure of $\mathrm{CeB}_{6} / \mathrm{Al}$ inoculant ribbon. In other words, the size of $\mathrm{CeB}_{6}$ particle is strongly dependent on the cooling rate that can greatly influence the settling 
velocity. According to the Stoke's Formula [30], the settling velocity is proportional to the square of the size of particles. Moreover, the settling velocity of the particles is deceased with the increment of cooling rate together with a reduction of gravity segregation. Therefore, the size of particles become smaller and the number of particles become more after solidification as shown in Figure 4. Furthermore, as we know, the degree of supper cooling is increased with the increasing of cooling rate, which in turn causes improved nucleation rate or refining effect [19]. For similar reason, $\mathrm{CeB}_{6}$ particles can also be refined, resulting in a size range of micron-scale to submicron-scale, as shown in the Figure 4. The representative energy dispersive spectrometer (EDS) results of the matrix marked in Figure 4a-c are given in Figure $4 \mathrm{~d}-\mathrm{f}$, respectively. It can be seen that the content of $\mathrm{Ce}$ elements in the aluminum matrix is obviously changed by melt spinning. It is indicated that the $\mathrm{Al}_{11} \mathrm{Ce}_{3}$ phase is inhibited due to fast solidification that is in accordance with the results of Figure $2 b$, leading to the super saturation Ce element increased in the matrix. The maximum particles size of different alloys and the Ce content in the matrix presents the opposite trend as shown in the Figure 5. Therefore, the submicron-scale $\mathrm{CeB}_{6}$ particles and the super saturation Ce element of the $\alpha$-Al matrix caused by the rapid solidification both contributed to the grain refinement.

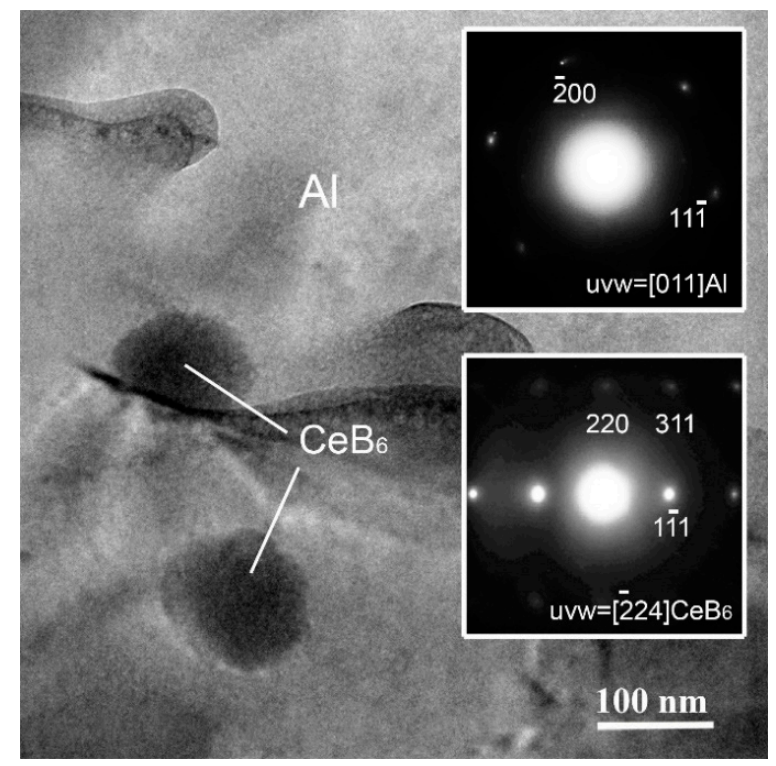

Figure 3. Transmission Electron Microscopy (TEM) characterization of the $\mathrm{CeB}_{6} / \mathrm{Al}$ ribbon $\mathrm{C} 2$.

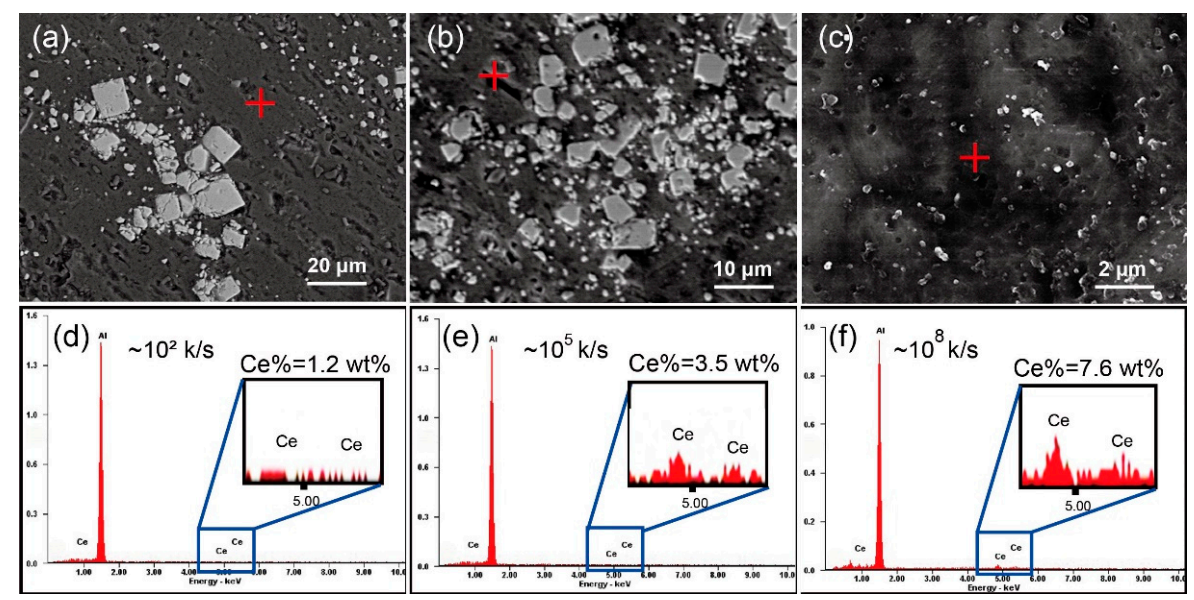

Figure 4. Scanning electron microscope (SEM) image of (a) C0 alloy, (b) C1 alloy, (c) C2 alloy. (d-f) are the energy dispersive spectrometer (EDS) spectrum of $(\mathbf{a}-\mathbf{c})$, respectively. 


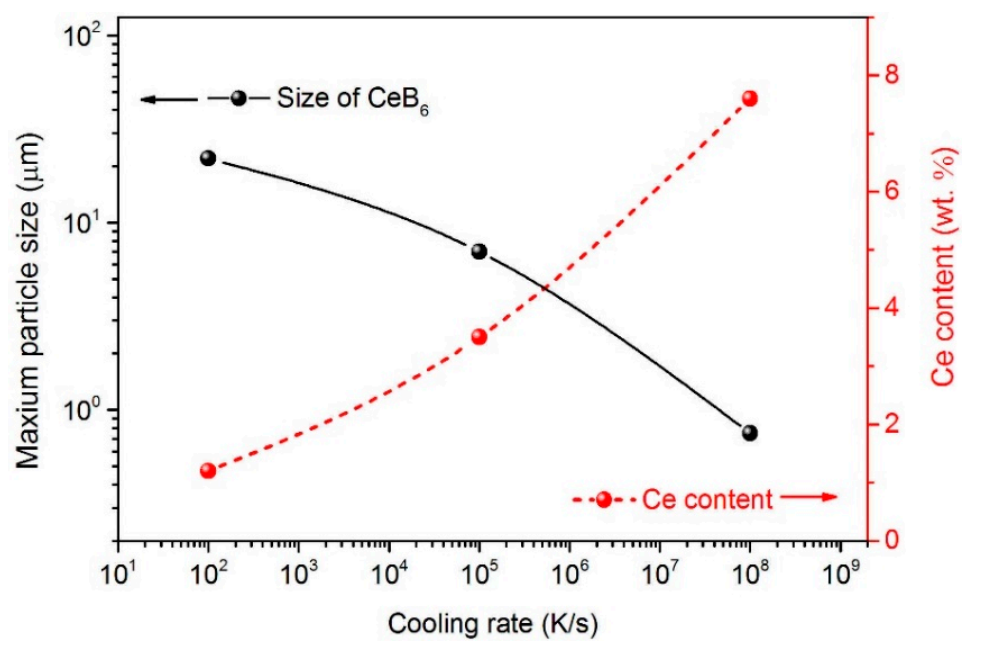

Figure 5. Cooling rate versus the particles size and the Ce content in the matrix.

\subsection{Effect of Holding Time on Grain Refinement of Melt-Spun Inoculants}

Figure 6 presents the microstructure of as-cast pure $\mathrm{Al}$ refined by $\mathrm{C} 1$ and $\mathrm{C} 2$ alloys after different holding time with an addition of $0.4 \%$, which has been verified as the best addition amount previously [25]. The morphology of as-cast $\mathrm{Al}$ is usually characterized by coarse dendrites. After adding $\mathrm{C} 1$ and $\mathrm{C} 2$ alloy, the colossal dendrites of the pure $\mathrm{Al}$ are significantly decreased as shown in Figure 6. Meanwhile, it is clear that the refining effect of $\mathrm{C} 2$ alloy is better than that of $\mathrm{C} 1$ alloy, as the holding time is similar. However, the macro metallographic (Figure 6) shows that the grain refining effect of both inoculants are somewhat decreased as the holding time is increased over $2 \mathrm{~min}$.

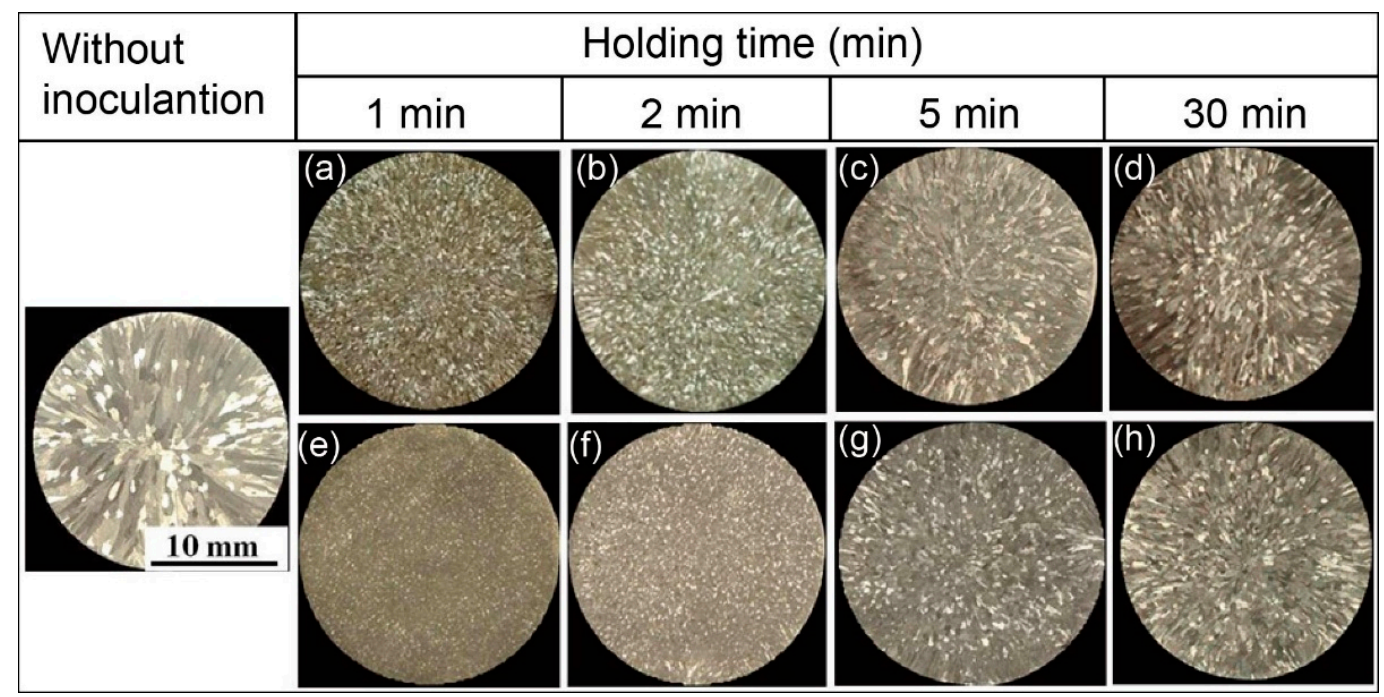

Figure 6. Optical metallographic images of as-cast aluminum samples after inoculation with different holding times: (a-d) are C1 alloy; (e-h) are C2 alloy.

Figure 7 displays grain size as a function of holding time of the inoculated samples with both inoculants, which clearly shows the variation tendency of grain refining efficiency. Notably, the samples refined by $\mathrm{C} 2$ alloy has relative smaller grain size than that of $\mathrm{C} 1$ at a same holding time. As the holding time is over $2 \mathrm{~min}$, both inoculant ribbons show obvious "fading" effect and C2 alloy seemed fading badly. As shown in the inset of Figure 7, for C2 alloy, the grains of the sample with long holding time is about three times bigger than that of short holding time. It is worth of noting that, with very 
short holding time ( 1 or $2 \mathrm{~min}$ ), melt-spun inoculants have the best grain refining effect, and the best holding time is reduced with the increased cooling rate. As well known, melt-spun ribbon is in an unstable and non-equilibrium status due to the fast solidification. Thus, the initial melting of melt-spun ribbon with high cooling rate is different from that of low-cooling-rate alloy, which might relate to the short holding time needed. Nevertheless, the present results show that this inoculant should be used with very short holding time, and it is very important for the future industrial application of this newly developed inoculant.

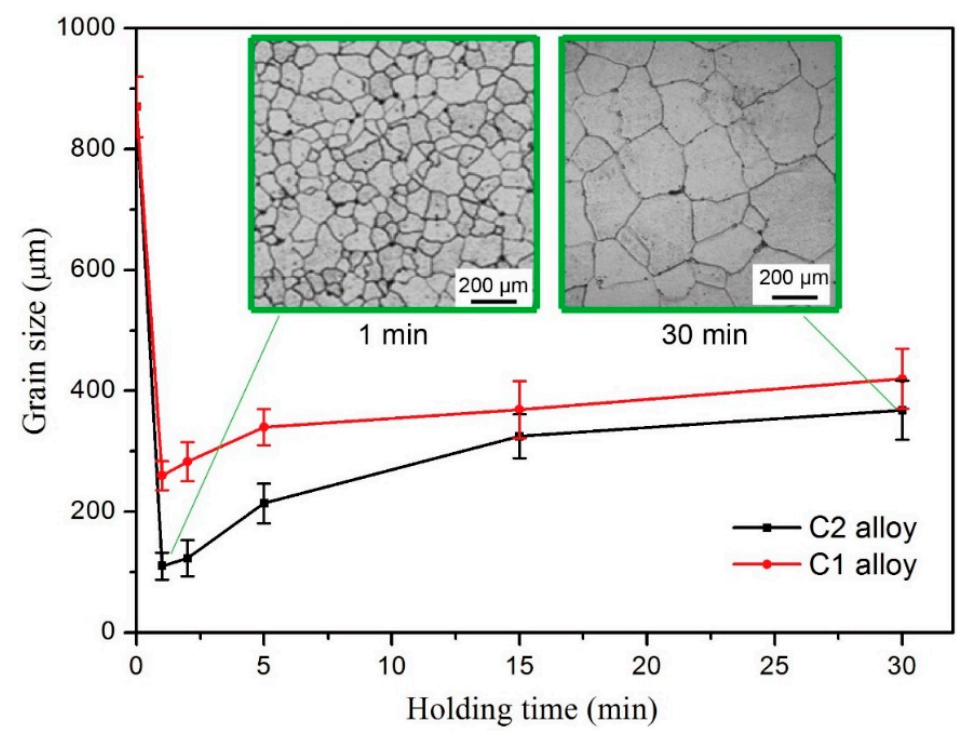

Figure 7. Grain size variations with holding time.

\section{Discussion}

Holding time is an important technical parameter for inoculants, which not only determines the detailed casting processing, but also affects the grain refining behavior of refiner particles. In a very short holding time, the inoculant occurs melting at first and begins to interact with the pre-melted $\mathrm{Al}$ melt. It is an important phenomenon that the best holding time of $\mathrm{C} 2$ alloy is shorter than $2 \mathrm{~min}$, which indicates that the melting behavior of inoculant shows great influence on the refining behavior. It has been found that large cooling rate caused two obvious changes on the inoculant: the supersaturated solid solution of $\mathrm{Ce}$ in the $\alpha-\mathrm{Al}$ matrix and the miniaturization of $\mathrm{CeB}_{6}$ particles. It is clear that the miniaturization of $\mathrm{CeB}_{6}$ particle will not affect the melting of ribbon, because the melting point of $\mathrm{CeB}_{6}$ is much higher than the holding temperature and $\mathrm{CeB}_{6}$ particles will not melt. Therefore, the melting of the ribbon mainly relates to the supersaturated solid solution of Ce. As shown in Figure 4, the content of cerium in the $\mathrm{Al}$ matrix is far more than the theoretical solid solubility of $\mathrm{Ce}$ in $\alpha$-Al on the phase diagram, which is very unstable in thermodynamics. In our opinion, the presence of excess Ce also makes the melting of Al matrix be very unstable at the holding temperature and tend to melt quickly. The sudden and homogeneous melting of ribbons will consume the energy of the Al liquid in the vicinity of the ribbon, and induce an instant large undercooling, which is beneficial for the nucleation of $\mathrm{Al}$ upon the surface of $\mathrm{CeB}_{6}$.

As it is known, the grain refining behavior of an inoculant is affected by the following two aspects: the size of refiner particles and the degree of undercooling [31]. According to Quested et al. [31], larger particles take part in the nucleation first (need small undercooling) and smaller particles become inactive due to the recalescence followed by the first nucleation events that increase the temperature in the vicinity of the smaller particles. Therefore, they indicated that the best size of refiner particles is about $400 \mathrm{~nm}$, and the smaller particles require relative large undercooling of which the ordinary casting cannot provided. In this case, the particle size of $\mathrm{CeB}_{6}$ is about $\sim 100 \mathrm{~nm}$, much smaller than 
the predicted value ( $400 \mathrm{~nm}$ ). It can be attributed to the instant large undercooling caused by the fast melting of Al matrix with super saturated Ce.

To explain the refining mechanism, a schematic diagram describing the nucleation and growth process of $\alpha-\mathrm{Al}$ dendrites is shown in Figure 8. When the $\mathrm{CeB}_{6} / \mathrm{Al}$ ribbons is added into pure $\mathrm{Al}$ melt, the $\mathrm{Al}$ matrix with super saturated Ce element will melt quickly into Ce-rich liquid, and the Ce atoms will fast diffuse in the inoculated melt driven by large concentration gradient. Such fast melting and diffusion processes will suddenly decrease the temperature of the local Al liquid around the unmelted $\mathrm{CeB}_{6}$ particles. Such a process will produce an instant large undercooling, which in turn activates the activity of small particles as nucleated substrate, homogeneously. Then, the inoculated melt is poured into the iron mold which can provide another undercooling, leading to the growth of the pre-nucleated $\mathrm{Al}$ crystals to complete the solidification process. When the holding time becomes longer, the undercooling caused by the fast melting of ribbons will disappear, resulting in the "fading" effect of the melt-spun ribbons. For an inference, the inoculants prepared by melt spinning might all require relative short holding time, due to the cooling rate effect according to the above analysis. In addition, the melt-spun $\mathrm{CeB}_{6} / \mathrm{Al}$ inoculant might be very appropriate for die-casting using iron or copper molds, which can provide a large degree of under cooling to activate the small refiner particles.

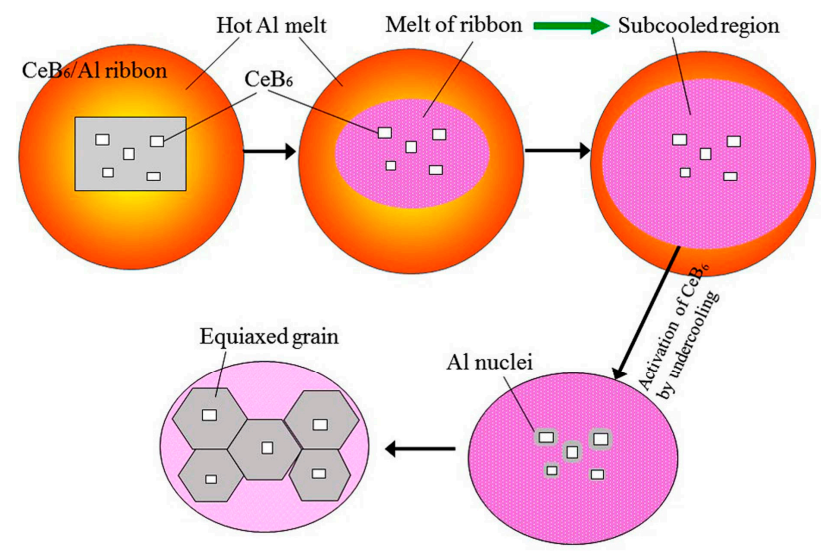

Figure 8. Schematic image showing the nucleation and growth process of $\alpha$-Al dendrites.

\section{Conclusions}

(1) The microstructure, chemical composition, and grain refining effect of $\mathrm{CeB}_{6} / \mathrm{Al}$ inoculant are all strongly depended on the cooling rate in preparation. With high cooling rate of $\sim 10^{8} \mathrm{~K} / \mathrm{s}$, the sizes of $\mathrm{CeB}_{6}$ particles can be reduced to $\sim 100 \mathrm{~nm}$ and the content of $\mathrm{Ce}$ in $\mathrm{Al}$ matrix is obviously increased to form supersaturated Al-Ce solid solution.

(2) The grain refining efficiency of melt-spun inoculant is strongly dependent on the holding time. The optimum holding time of the inoculation is within $2 \mathrm{~min}$, which is very valuable and crucial for future industrial application.

(3) A stationary grain refinement model is proposed to explain the detailed inoculation mechanism of melt-spun $\mathrm{CeB}_{6} / \mathrm{Al}$ composite inoculant, which agrees well with the very short holding time of $\mathrm{CeB}_{6} / \mathrm{Al}$ composite inoculant.

Acknowledgments: This work was supported by the Nature Science Foundation of Tianjin (No. 14 JCYBJC17900), Key projects of the Natural Science Foundation of Hebei Province (No. E2013209207 and No. E2016202406) and Graduate Student Innovation Fund Project of Hebei province (No. 220056).

Author Contributions: Shuiqing Liu and Chunxiang Cui conceived and designed the experiments; Shuiqing Liu performed the experiments and wrote the original manuscript; Xin Wang suggested improvement of the experiments and revised the manuscript; Jiejie Shi, Sen Cui, and Peng Chen contributed materials, reagents, and analysis tools, respectively. Nuo Li contributed in revising some grammar and experimental data analysis.

Conflicts of Interest: The authors declare no conflict of interest. 


\section{References}

1. Murty, B.S.; Kori, S.A.; Chakraborty, M. Grain refinement of aluminum and its alloys by heterogeneous nucleation and alloying. Int. Mater. Rev. 2002, 47, 3-29. [CrossRef]

2. Easton, M.A.; Stjohn, D.H. A model of grain refinement incorporating alloy constitution and potency of heterogeneous nucleant particles. Acta Mater. 2001, 49, 1867-1878. [CrossRef]

3. Li, Q.L.; Xia, T.D.; Lan, Y.F.; Zhao, W.J.; Fan, L.; Li, P.F. Effect of rare earth cerium addition on the microstructure and tensile properties of hypereutectic Al-20\%Si alloy. J. Alloys Compd. 2013, 562, $25-32$. [CrossRef]

4. Easton, M.A.; StJohn, D.H. Improved prediction of the grain size of aluminum alloys that includes the effect of cooling rate. Mater. Sci. Eng. A 2008, 486, 8-13. [CrossRef]

5. Verma, A.; Kumar, S.; Grant, P.S.; O'Reilly, K.A.Q. Influence of cooling rate on the Fe intermetallic formation in an AA6063 Al alloy. J. Alloys Compd. 2013, 555, 274-282. [CrossRef]

6. Rajabi, M.; Simchia, A.; Davamia, P. Microstructure and mechanical properties of Al-20Si-5Fe-2X (X=Cu, $\mathrm{Ni}, \mathrm{Cr}$ ) alloys produced by melt-spinning. Mater. Sci. Eng. A 2008, 492, 443-449. [CrossRef]

7. Chen, Z.W.; Lei, Y.M.; Zhang, H.F. Structure and properties of nanostructured A357 alloy produced by melt spinning compared with direct chill ingot. J. Alloys Compd. 2011, 509, 7473-7477. [CrossRef]

8. Dong, T.S.; Cui, C.X.; Liu, S.J.; Yang, L.J.; Sun, J.B. Influence of rapid solidification of Cu-P intermediate alloy on wear resistance of Al-Si alloy. Rare Met. Mater. Eng. 2008, 37, 686-689.

9. Liu, X.B.; Osawa, Y.; Takamori, S.; Mukai, T. Grain refinement of AZ91 alloy by introducing ultrasonic vibration during solidification. Mater. Lett. 2008, 62, 2872-2875. [CrossRef]

10. Quested, T.E.; Dinsdale, A.T.; Greer, A.L. Thermodynamic modelling of growth restriction effects in aluminum alloys. Acta Mater. 2005, 53, 1323-1334. [CrossRef]

11. StJohn, D.H.; Qian, M.; Easton, M.A.; Cao, P. The Interdependence Theory: The relationship between grain formation and nucleant selection. Acta Mater. 2011, 59, 4907-4921. [CrossRef]

12. Quested, T.E.; Greer, A.L. Grain refinement of Al alloys: Mechanisms determining as-cast grain size in directional solidification. Acta Mater. 2005, 53, 4643-4653. [CrossRef]

13. Pineda, D.A.; Martorano, M.A. Columnar to equiaxed transition in directional solidification of inoculated melts. Acta Mater. 2013, 61, 1785-1797. [CrossRef]

14. Dong, X.X.; He, L.J.; Mi, G.B.; Li, P.J. Two directional microstructure and effects of nanoscale dispersed Si particles on microhardness and tensile properties of AlSi7Mg melt-spun alloy. J. Alloys Compd. 2015, 618, 609-614. [CrossRef]

15. Wang, K.; Cui, C.X.; Wang, Q.; Liu, S.J.; Gu, C.S. The microstructure and formation mechanism of core-shell-like $\mathrm{TiAl}_{3} / \mathrm{Ti}_{2} \mathrm{Al}_{20} \mathrm{Ce}$ in melt-spun Al-Ti-B-Re grain refiner. Meter. Lett. 2012, 85, 153-156. [CrossRef]

16. Uzun, O.; Karaaslan, T.; Gogebakan, M.; Keskin, M. Hardness and microstructural characteristics of rapidly solidified Al-8-16 wt. \% Si alloy. J. Alloys Compd. 2002, 376, 149-157. [CrossRef]

17. Takayama, S. Amorphous structures and their formation and stability. J. Mater. Sci. 1976, 11, $164-185$. [CrossRef]

18. Kalay, Y.E.; Chumbley, L.S.; Anderson, I.E.; Napolitano, R.E. Characterization of hypereutectic Al-Si powders solidified under far-from equilibrium conditions. Metall. Mater. Trans. A 2007, 38, 1452-1457. [CrossRef]

19. Xu, C.L.; Wang, H.Y.; Qiu, F.; Yang, Y.F.; Jiang, Q.C. Cooling rate and microstructure of rapidly solidified Al-20 wt. \% Si alloy. Mater. Sci. Eng. A 2006, 417, 275-280. [CrossRef]

20. Karaköse, E.; Keskin, M. Effect of solidification rate on the microstructure and microhardness of a melt-spun Al-8Si-1Sb alloy. J. Alloys Compd. 2009, 479, 230-236. [CrossRef]

21. Dong, X.X.; He, L.J.; Li, P.J. Gradient microstructure and multiple mechanical properties of AlSi9Cu alloy ribbon produced by melt spinning. J. Alloys Compd. 2014, 612, 20-25. [CrossRef]

22. Zhang, Z.H.; Bian, X.F.; Wang, Y.; Liu, X.F. Microstructure and grain refining performance of melt-spun Al-5Ti-1B master alloy. Mater. Sci. Eng. A 2003, 352, 8-15. [CrossRef]

23. Tong, X.C.; Fang, H.S. Al-TiC composites In Situ-processed by ingot metallurgy and rapid solidification technology: Part I. Microstructural evolution. Metall. Trans. A 1998, 29, 875-891. [CrossRef]

24. Brochu, M.; Portillo, G. Grain refinement during rapid solidification of aluminum-zirconium alloys using electrospark deposition. Metall. Trans. 2013, 6, 934-939. [CrossRef] 
25. Liu, S.Q.; Wang, X.; Cui, C.X.; Zhao, L.C.; Liu, S.J.; Chen, C. Fabrication, microstructure and refining mechanism of in situ $\mathrm{CeB}_{6} / \mathrm{Al}$ inoculant in aluminum. Mater. Des. 2015, 65, 432-437. [CrossRef]

26. Liu, S.Q.; Wang, X.; Cui, C.X.; Zhao, L.C. Enhanced grain refinement of in situ $\mathrm{CeB}_{6} / \mathrm{Al}$ composite inoculant on pure aluminum by microstructure control. J. Alloys Compd. 2017, 701, 926-934. [CrossRef]

27. Nie, J.F.; Liu, X.F.; Wu, Y.Y. The influences of B dopant on the crystal structure and nucleation ability of TiC in the Al melt. Meter. Res. Bull. 2013, 48, 1645-1650. [CrossRef]

28. Wang, K.; Cui, C.X.; Wang, Q.; Qi, Y.M.; Wang, C. Fabrication of in situ AlN-TiN/Al inoculant and its refining efficiency and reinforcing effect on pure aluminum. J. Alloys Compd. 2013, 547, 5-10. [CrossRef]

29. Wang, X.; Gong, P.; Yao, K.F. Mechanical behavior of bulk metallic glass prepared by copper mold casting with reversed pressure. J. Mater. Process Technol. 2016, 237, 270-276. [CrossRef]

30. Sjöberg, L.E. A general model for modifying Stokes' formula and its least-squares solution. J. Geod. 2003, 77, 459-464. [CrossRef]

31. Quested, T.E.; Greer, A.L. The effect of the size distribution of inoculant particles on as-cast grain size in aluminum alloy. Acta Mater. 2004, 52, 3859-3868. [CrossRef]

(C) 2017 by the authors. Licensee MDPI, Basel, Switzerland. This article is an open access article distributed under the terms and conditions of the Creative Commons Attribution (CC BY) license (http:// creativecommons.org/licenses/by/4.0/). 